\title{
OS LIMITES DA GINÁSTICA LABORAL PARA COMPREENSÃO DOS DETERMINANTES DE SAÚDE DE TRABALHADORES BANCÁRIOS ${ }^{1}$
}

\author{
Jéssica Felix Nicácio Martinez \\ Universidade Federal de Goiás, Goiânia. Goiás, Brasil \\ Edgard Matiello Júnior \\ Universidade Federal de Santa Catarina, Florianópolis, Santa Catarina, Brasil
}

\begin{abstract}
Resumo
Nas instituições bancárias brasileiras, encontramos um duplo movimento: os banqueiros, com poder político e econômico, que lhes asseguram lucros de bilhões de reais anualmente; e os trabalhadores, que enfrentam formas cada vez mais intensas de dominação do trabalho e enfraquecimento de suas capacidades de resistências. Nossos objetivos foram anunciar alguns determinantes de saúde dos trabalhadores bancários e apresentar uma possibilidade alternativa de educação física relacionada à saúde, empregando os pressupostos da pesquisa-ação. Concluímos que a intervenção pedagógica superou alguns limites identificados nas propostas hegemônicas de ginástica laboral, pois buscamos atender as necessidades e aspirações da categoria pelo entendimento do seu processo saúde-doença.
\end{abstract}

Palavras-chave: Saúde do Trabalhador. Educação Física. Ginástica Laboral.

\section{Introdução}

$\mathrm{N}_{\mathrm{t}}^{\mathrm{s}}$ este artigo pretendemos discorrer principalmente sobre dois contextos que, a princípio, não dizem respeito um ao outro, a não ser por uma associação ingênua, e/ou oportunista, de ambas as partes envolvidas. Um deles diz respeito, de forma geral, ao setor bancário, cujas mudanças organizacionais mais recentes vêm intensificando a exploração humana e deteriorando as condições de vida e de saúde dos trabalhadores. O outro contexto que buscamos discutir é o da gi-

1-Este trabalho é um recorte da dissertação de mestrado em Educação Física intitulada "Superações da Educação (Física) Bancária pela Saúde Coletiva: Pesquisaação no Sindicato em Florianópolis", realizada na Universidade Federal de Santa Catarina. Durante os últimos seis meses deste curso de pós-graduação houve concessão de bolsa de estudos da CAPES. 
nástica laboral, que vem se consolidando como uma proposta de atividade física no ambiente de trabalho, e que, no entanto, se desenvolve desprovida de reflexões teórico-metodológicas, políticas e, principalmente, éticas sobre suas verdadeiras contribuições à saúde do trabalhador.

Quanto à ingenuidade e/ou oportunismo que fizemos menção, isto se sustenta na medida em que são tantas e importantes as perdas acumuladas pela categoria bancária nas últimas décadas, que uma atividade com as características da ginástica laboral se apresenta de forma, no mínimo, insuficiente para transformar a essência daquilo que, de fato, degrada a vida dos trabalhadores, ou seja, o próprio modo de produção e exploração capitalista aí instalado. Pelo contrário, da forma como ela vem sendo requisitada pelo empresariado e é desenvolvida pela Educação Física, representa muito mais uma maneira de acomodação das tensões sociais; de dissipação das fortes contradições do processo produtivo; de despolitização do ato laboral e desmobilização da luta sindical; de individualização da conquista pela saúde e de compensação paliativa aos desgastes físicos e psíquicos dos trabalhadores (MARTINEZ, 2007; MATIELLO JÚNIOR et. al., 2008).

Como intuito de buscar superar estes limites, nos apoiamos nos referenciais da Saúde Coletiva/Epidemiologia Crítica (BREILH, 2006) para compreender o processo saúde-doença dos trabalhadores, como também da Educação Problematizadora de Paulo Freire e de leituras de pedagogias críticas $^{2}$ da Educação Física para fundamentar nossa prática pedagógica. Assim, neste artigo nossos objetivos foram anunciar alguns determinantes de saúde dos trabalhadores bancários, buscando evidenciar as limitações das propostas hegemônicas de ginástica laboral para atuar neste contexto. E como objetivo secundário, buscamos apresentar, de forma sintética, uma possibilidade alternativa de educação física relacionada à saúde implementada junto ao Sindicato dos Bancários de Florianópolis e Região.

\section{Reestruturação produtiva dos bancos e desestruturação da saúde dos bancários}

O sistema financeiro tem papel de destaque no amplo processo de globalização mundial, se fortalecendo por meio de estratégias de in-

2-Como, por exemplo, as obras de Kunz (2003) e Coletivo de Autores (1992).

Pensar a Prática, Goiânia, v. 15, n. 3, p. 551-820, jul./set. 2012 
fluência política que acabam por pressionar diversos governos na adoção de medidas que favoreçam a circulação e acumulação financeira. No Brasil, algumas destas iniciativas são: i) política de privatização das empresas estatais; ii) manutenção de altas taxas de juros que atrai capital especulativo internacional; iii) abertura de bolsas brasileiras para aplicações internacionais; e iv) adoção de uma série de medidas que facilitam a participação dos bancos estrangeiros no país (MINELLA, 1997).

A atividade bancária nacional se caracterizou pela alta lucratividade, favorecida pelo longo período em que vigoraram os altos índices de inflação. No auge desta, ao final da década de oitenta, o setor financeiro chegou a representar $14 \%$ do PIB brasileiro (LARANGEIRA, 1997). Jinkings (1996) informa que os lucros auferidos pelos bancos, em função das altas taxas inflacionárias, foram importantes para o investimento maciço e generalizado em tecnologia, sendo que somente nos anos 1992 e 1993 os banqueiros investiram, respectivamente, US\$ 2 bilhões e US\$ 3 bilhões na compra de computadores e softwares, enquanto que o emprego bancário já vinha acumulando taxas negativas desde 1990.

Outro marco histórico na concorrência no setor foi o ano 1994. Com a queda abrupta da inflação devido à implantação do Plano Real, desencadeou-se a intensificação do processo de reestruturação produtiva. Ele se caracterizou pela combinação de inovações tecnológicas com novas formas de gestão que, conjuntamente, tiveram impactos decisivos sobre o perfil dos trabalhadores "sobreviventes", sobre a atuação dos sindicatos e sobre as negociações coletivas no decorrer dos anos 90 (ARAÚJO; CARTONI; JUSTO, 2001; MERLO; BARBARINI, 2002; GRISCI; BESSI, 2004).

$\mathrm{Na}$ essência desse processo de acumulação dos banqueiros (de capital e respectivo poder político e econômico) e melhoria (restritiva e contraditória) dos serviços aos clientes, temos a intensificação da reestruturação produtiva do setor bancário nacional, que, portanto, deve ser compreendida como incluída no processo de reestruturação do próprio capitalismo. Diante de tantos determinantes que degradam a vida dos bancários nos concentramos em três fenômenos sociais que, segundo Segnini (1999), caracterizam esse processo: terceirização, precarização/intensificação do trabalho e elevado desemprego.

$\mathrm{O}$ recurso à terceirização tem sido utilizado com o intuito primordial de reduzir custos, principalmente as atividades de baixa qualifica- 
ção, através da exclusão de parte dos trabalhadores do mercado regular de trabalho. Os empregados que prestam serviços de terceirização recebem salários menores do que o piso da categoria e não têm os mesmos benefícios. Não obstante, contribuem para o enfraquecimento do movimento sindical, pois muitos demitidos passam a trabalhar para as empresas terceirizadas, exercendo, frequentemente, as mesmas funções de antes, mas deixando em muitos casos, de pertencer à categoria (LARANGEIRA, 1997; SEGNINI, 1999). Soma-se a esta problemática a terceirização de atividades feitas anteriormente por profissionais altamente qualificados, atuantes em departamentos como os de recursos humanos, treinamento, informática e marketing, que são substituídos por serviços temporários de consultoria/assessoria, sem vínculos trabalhistas.

Quanto à intensificação do trabalho, Araújo, Cartoni e Justo (2001) consideram que uma de suas origens é a flexibilização funcional, ou seja, a incorporação de várias tarefas com a mesma rotina de horas trabalhadas. Assim:

O novo profissional deverá ser especializado em vendas, necessitando de conhecimentos sobre o mercado financeiro, sobre a utilização de softwares de matemática financeira, além da aquisição de atitudes e comportamentos de saber-vender. (LARANGEIRA, 1997, p.118).

Este novo perfil exigido tende a desqualificar os funcionários com muitos anos de serviço, por apresentarem dificuldades em acompanhar as mudanças tecnológicas. Contudo, isto não é suficiente para explicar o elevado índice de desemprego de trabalhadores escolarizados e qualificados $^{3}$, pois se em 1990 os bancários brasileiros representavam 1,7 milhões de trabalhadores, em 1995 esse número foi brutalmente reduzido para 400 mil, ou seja, mais de um milhão de pessoas desempregadas em apenas cinco anos (RIGOTTO, 1998).

De acordo com Jinkings (2002), o emprego bancário é afetado di-

3-No período de 1994 a 1996 observou-se uma elevação do nível de escolaridade da categoria, isto é, bancários com nível superior completo e com pós-graduação strictu-senso passaram de $28,6 \%$ para $34,5 \%$ e o número de bolsas concedidas pelos bancos para formação em cursos de graduação passou de 35\% em 1995 para 61\% em 1996 (LARANGEIRA, 1997).

Pensar a Prática, Goiânia, v. 15, n. 3, p. 551-820, jul./set. 2012 
retamente pela incorporação dos pressupostos dos programas de "qualidade total", que direcionam os novos "negócios" dos bancos, nos quais a concepção de qualidade significa produzir mais com menores custos. Os ajustes organizacionais determinados por estes programas incluem intensificação tecnológica, desenvolvimento de um sofisticado sistema de comunicação empresa-trabalhador, criação de equipes "de qualidade" nos locais de trabalho e contratações e remunerações flexíveis de acordo com o desempenho do funcionário e da sua unidade de trabalho no cumprimento de metas.

Uma pesquisa promovida pelo DIESAT (Departamento Intersindical de Estudos e Pesquisas de Saúde e Ambientes de Trabalho) na década de noventa, citada por Jinkings (1996), já informava que as causas de tensão e cansaço apontadas pelos bancários eram o ritmo intenso de trabalho, a pressão por produtividade, as formas de controle exercidas pelas chefias, grande carga de responsabilidade e a exigência dos clientes em casos de atendimento ao público. Outros problemas como o de estresse e sintomas psicoemocionais, de coluna, estômago ou fígado e de visão também foram lembrados.

Os processos de automação e intensificação do trabalho evidenciaram a problemática da saúde, sobretudo das LER ${ }^{4}$ (Lesões por Esforços Repetitivos), com enorme crescimento na década de noventa, fato que exigiu frequentes negociações coletivas pela organização sindical dos bancários. Pennella (2000), apresentando o Programa de Prevenção elaborado e coordenado pela Faculdade de Saúde Pública da USP, estimou que em cada 100 bancários dez já tenham lesões e outros dez apresentam os sintomas iniciais da doença.

A invisibilidade das LER representa mais um elemento nefasto e contribui para que colegas de trabalho e familiares discriminem os doentes e minimizem as dificuldades encontradas, já que a doença não se manifesta visivelmente. Merlo e Barbarini (2002, p.116), realizando estudos com caixas executivos, presenciaram as dúvidas e desconfianças entre os bancários desta função, e concluíram que o medo faz com

4-Em 1997, com a nova Norma de Avaliação de Incapacidade do Instituto Nacional de Seguridade Social (INSS), a terminologia LER é modificada para DORT (Distúrbios Osteomusculares Relacionados ao Trabalho). No entanto, segundo Verthein e Minayo-Gomez (2000) este posicionamento do INSS tem como pressuposto a descaracterização da relação doença e trabalho, sugerindo que o sujeito é predisposto a adoecer e de uma saúde como capacidade para o trabalho.

Pensar a Prática, Goiânia, v. 15, n. 3, p. 551-820, jul./set. 2012 
que estes trabalhadores "recorram à estratégia coletiva do silêncio, negando o sofrimento dos outros e calando sobre o próprio".

Desta forma, o bancário acaba submetendo-se a situações no trabalho que prejudicam sua integridade, seja ela de ordem física, psicológica, intelectual e social. Nesse sentido, o estudo de Murofuse e Marziale (2001) evidencia as principais mudanças no trabalho e na vida de um grupo de trabalhadores do setor no município de Cascavel/PR. A disposição, dedicação, responsabilidade, satisfação, reconhecimento profissional, renúncia aos projetos pessoais em favor das necessidades da empresa, foram elementos comuns encontrados na auto-descrição de suas vidas. Aliados a equipamentos inadequados aquém das necessidades fisiológicas dos trabalhadores e as dificuldades no diagnóstico médico das doenças ocupacionais, os quais interferem e alteram o ritmo de produtividade no trabalho, isto lhes causava agravamento dos sofrimentos físico e mental.

Em uma pesquisa (LPT/UnB; SINDICATO DOS BANCÁRIOS DE BRASÍLIA, 2004) realizada com três bancos públicos, identificouse que cerca de $13 \%$ dos bancários são alcoolistas. Os gerentes estão entre as funções que apresentam maior frequência (19\%) com problemas relacionados ao uso abusivo ou nocivo de álcool. Apesar da maioria dos cargos de gerente ser ocupado por homens $(84,7 \%)$, o número de mulheres nestas funções tem aumentado ${ }^{5}$, assim como a dependência de álcool (15,3\% das mulheres apresentaram problemas).

Segundo dados da Agência Brasil (2006), dos 2.609 bancários de 28 diferentes bancos públicos e privados no Brasil, mais de $40 \%$ sofrem agressões morais no trabalho e 30,52\% se sentem estressados. De 2000 a 2004, o Instituto Nacional de Seguridade Social (INSS) divulgou o aumento de $65 \%$ no número de diagnósticos de trabalhadores bancários com transtornos mentais (SINDICATO DOS BANCÁRIOS DE PERNAMBUCO, 2006).

Ainda sobre este assunto, de acordo com estudo com caixas do Rio de Janeiro, as agressões dos clientes e o medo constante em cometer erros trazem consequências negativas à saúde mental destes trabalhadores. Estes bancários consideram seu trabalho repetitivo, agressivo,

5-Apesar do aumento no número de trabalhadoras em instituições bancárias, ainda persistem as formas de discriminação ocupacional e salarial, assim como, de exclusão econômica da mulher, em diferentes funções, do mercado de trabalho (JINKINGS, 2002).

Pensar a Prática, Goiânia, v. 15, n. 3, p. 551-820, jul./set. 2012 
monótono e que exige intensa atenção, além de relatos da existência de fiscalização velada exercida pelos colegas, chegando a ponto de denominar alguns bancários de "boing" ou "teco-teco", segundo a velocidade que realizam os atendimentos (PALÁCIOS, DUARTE; CÂMARA, 2002).

Enfim, neste item apresentamos, de forma sintética, as repercussões da reestruturação produtiva nas condições de vida e saúde dos bancários com o objetivo de evidenciar alguns dos determinantes de saúde dos bancários. E é a partir deste quadro complexo que buscamos discutir os limites da ginástica laboral para atuar neste contexto de exploração e intensificação do trabalho.

\section{A Educação Física e as lutas dos bancários: encontro na saúde}

Com base nos limites contidos nas propostas hegemônicas da ginástica laboral ${ }^{6}$, como integrantes de um grupo de pesquisa denominado 'Vivendo Educação Física e Saúde Coletiva', temos nos apoiado nesses dois campos de conhecimento para alcançarmos alternativas realistas que nos permitam atuar na defesa dos interesses dos trabalhadores perante as fortes agressões que sofrem para as quais muitas vezes não reúnem forças e organização suficientes para reação.

Neste contexto, partimos do reconhecimento do Sindicato como instituição legítima para defesa dos interesses dos trabalhadores, buscando seu fortalecimento contra as estruturas de poder que minam a resistência coletiva. Encontramos então o Sindicato dos Bancários de Florianópolis e Região como parceiro para um projeto de pesquisa e a construção da intervenção pedagógica intitulada Projeto Educação Física com Saúde, desenvolvido coletivamente, no contato direto com os sindicalizados.

Como anunciamos na introdução, este trabalho foi orientado pelas bases da Epidemiologia Crítica, que compreende a saúde como decorrente do contexto social, cujo movimento de gênese e reprodução é possibilitado pelos processos individuais e coletivos, que se articulam e se determinam mutuamente. O olhar dialético nos auxilia a compreender tanto os elementos mais amplos da estrutura político-ideológica da sociedade como os processos particulares de uma classe ou um gru-

6-Críticas as propostas hegemônicas de ginástica laboral podem ser verificadas em Martinez (2007) e Matiello Júnior et. al. (2008).

Pensar a Prática, Goiânia, v. 15, n. 3, p. 551-820, jul./set. 2012 
po, e a realidade familiar e pessoal dos sujeitos (BREILH, 2006).

Assumimos também como categoria central o perfil de reprodução social, que designa o conjunto da vida social caracterizada pelas formas de trabalhar e consumir; pelas relações que os seres humanos estabelecem entre si; pela forma com que transformam a natureza e formas pelas quais realizam a distribuição e o intercâmbio dos bens socialmente produzidos; pelas instituições que geram e pelo nível de consciência que alcançam (CAMPAÑA, 1997).

E foi a partir destas categorias, apesar de suas complexidades, que fizemos um exercício, cuidadoso e demorado, de compreensão da nossa realidade de investigação. Deste modo, formalizamos dois pressupostos do estudo:

- O trabalho é determinante no processo saúde-doença dos bancários e, por esta razão, foi fundamental investigarmos para além do que as aparências nos indicam, ou seja, os elementos históricos, econômicos e sociais da reestruturação produtiva dos bancos brasileiros que mudaram profundamente o trabalho dos bancários, sua saúde e a organização sindical;

- Os trabalhadores, neste contexto, não estão somente expostos a danos à sua saúde, mas sim impostos a um processo que de fato deteriora suas vidas, lhes acarretando uma alta vulnerabilidade epidemiológica.

O projeto também incorporou as idéias desenvolvidas por Arruda (1997), preconizando que a educação que interessa à classe trabalhadora deve ter como base o ser humano integral, sendo nosso compromisso formar a vontade humana e a intencionalidade do trabalhador; e contribuir para que ele possa teorizar sobre sua prática, ajudando-o a sair da visão imediatista, ativista e empirista, conquistando, cada vez mais, uma visão estratégica e totalizante da realidade.

Como proposta para a prática corporal, optamos pela Hatha Yoga ${ }^{7}$ para orientar os movimentos e posturas corporais (ásanas) nas aulas. Este tipo de yoga difere dos demais porque utiliza como princípio o aperfeiçoamento do corpo, pois "a sabedoria hindu, fundamento filosófico da Hatha Yoga, ensina que espírito e corpo não são mais que as-

7-Optamos por oferecer aulas de yoga e massagens (auto-aplicadas), devido à experiência acumulada da pesquisadora nestes conteúdos, mas principalmente por acreditarmos que tais práticas poderiam contribuir com a diminuição do elevado grau de estresse da categoria, cujas tensões sobrecarregam as estruturas físicas e emocionais dos trabalhadores.

Pensar a Prática, Goiânia, v. 15, n. 3, p. 551-820, jul./set. 2012 
pectos diferentes de uma mesma unidade essencial" (HERMÓGENES, 2004, p. 39). Por esta razão o corpo tem atenção especial neste tipo de prática, o que não diminui a importância de exercícios para melhorar a respiração (pranayamas) e a meditação.

Com relação aos participantes do projeto Educação Física com Saúde houve presença permanente de um dirigente do sindicato anteriormente referido e, esporadicamente, outras quatro pessoas da instituição. Entre os bancários que participaram com frequência, a maioria é mulher, em torno de oito, e quatro homens, em média. Os trabalhadores têm por volta de quarenta anos de idade, vinte anos de emprego em bancos e todos trabalham em bancos públicos ${ }^{8}$.

Na nossa intervenção buscamos criar espaços de práticas corporais e diálogo, que também orientaram a preparação das aulas. Ao final das aulas, a pesquisadora estimulava os alunos para que refletissem sobre alguns questionamentos, buscando analisar conjuntamente alguns conceitos, aproveitando cada oportunidade para, por exemplo, discutirmos que saúde não se ganha, se conquista, e afirmando que saúde e qualidade de vida são aspirações coletivas. As discussões eram resgatadas no início da aula seguinte. Os questionamentos que incentivamos foram, por exemplo: Quais as vantagens de ficar doente? (pergunta que ajudava muito a discutir as contradições inerentes a essa condição de vida); O que é ter saúde?; O que é ser bancário?. Isto nos propiciou dialogar sobre conceitos de saúde, as transformações do mundo do trabalho, número de demissões, terceirizações e discutir o vídeo 'Banco de Horrores', que mostra a realidade e dificuldades dos bancários diagnosticados com LER.

O projeto também teve momentos de recuos, pois não conseguíamos despertar o interesse e o diálogo sem que os alunos nos permitissem confiança. Somente após dois meses de aulas sentimos que os alunos estavam mais seguros e confortáveis para compartilhar suas dores, problema e tema muito presente nas aulas. Inicialmente a dor foi compreendida como um problema individual, mas ao longo do tempo foi reconhecido como próprio da categoria; portanto, coletivo. Mesmo porque, vários bancários estavam participando do projeto afastados de seu trabalho por licença médica, sendo os principais pro-

8- Do total de 40 inscritos, trinta fizeram pelo menos uma aula, sendo quinze da Caixa Econômica Federal, onze do Banco do Brasil, nove do BESC, dois do Banrisul, dois do Santander/Banespa e um do Itaú.

Pensar a Prática, Goiânia, v. 15, n. 3, p. 551-820, jul./set. 2012 
blemas a fibromialgia, LER, recente isquemia cerebral, depressão, entre outros. Todos eles foram compartilhados entre nós, nas aulas, e tornou-se natural na medida em que diziam sem constrangimentos que notavam melhoras ou que tinham faltado nos encontros porque sentiam muitas dores.

Com relação às dores diariamente relatadas no início do projeto e durante as práticas, os participantes da intervenção também compartilharam as melhoras de suas condições de saúde:

Eu comecei em um processo muito mal da fibromialgia, eu falei não sei até aonde eu vou [...] E assim que a fibromialgia passava, eu ia exigindo, melhorou bastante e procuro ir no meu limite, sinto aquela dorzinha, mas não sinto dor depois. Eu acho que eu melhorei, assim eu larguei os medicamentos, não tomo mais nada [...] Eu acho que é importante dar um depoimento porque eu comecei assim num processo muito doloroso (BEC) ${ }^{9}$.

O que eu senti depois de praticar aqui é uma melhora física, a gente se sente mais disposto, com mais ânimo, suporta a vida melhor, enfim. Realmente está me ajudando, me sinto mais flexível e, principalmente, eu sentia dores no pescoço, na cervical e isso melhorou bastante, ainda não melhorou totalmente, mas hoje eu consigo ter uma melhor postura. (BEA).

Quando os trabalhadores conseguem se perceber como categoria, superando a ideia de aglomerado de indivíduos, participam de um processo de construção pedagógica e de formação política advindo do reconhecimento dos limites postos pela realidade, denominado de consciência reivindicativa (TUMOLO, 2002). Desta forma, qualificam o conhecimento adquirido na prática da militância e compreendem a necessidade de se organizarem e reunirem forças para lutar por seus direitos.

De acordo com Seligmann-Silva (1994), a solidariedade e o compromisso desempenham papel fundamental no trabalho, fortalecendo a saúde. As pessoas se tornam aptas a ter saúde quando se desperta autonomia, espírito de cooperação coletiva e convivência, respeitando suas

9-Com o intuito de preservar a identidade dos entrevistados, seus nomes foram substituídos pela denominação de bancos privatizados ou federalizados.

Pensar a Prática, Goiânia, v. 15, n. 3, p. 551-820, jul./set. 2012 
experiências em um movimento dinâmico de integrar, solidarizar e conscientizar (DA ROS; VIEIRA; CUTOLO, 2005).

\section{Considerações finais}

Para finalizar, apresentamos, de forma simplificada, um estudo com as principais diferenças entre a intervenção pedagógica apresentada neste artigo e as propostas hegemônicas de ginástica laboral (Quadro 1$)^{10}$ :

\begin{tabular}{|c|c|c|}
\hline $\begin{array}{r}\text { Propostas de atuação da } \\
\text { Educação Física } \\
\text { Eixos de análise } \\
\end{array}$ & Projeto Educação Fisica com Saúde & $\begin{array}{l}\text { Propostas hegemônicas de ginástica } \\
\text { laboral }\end{array}$ \\
\hline Epistemológico & $\begin{array}{l}\text { Pautado na Epidemiologia Crítica e Saúde } \\
\text { Coletiva } \\
\text { Compreende a saúde-doença como um } \\
\text { processo dinâmico e contraditório, que } \\
\text { envolve desde estruturas ideológicas até a } \\
\text { singularidade dos sujeitos. }\end{array}$ & $\begin{array}{l}\text { Fundamentadas em bases empírico- } \\
\text { analíticas do Positivismo Científico } \\
\text { Entende a saúde de forma isolada, } \\
\text { respaldada em bases biológicas e } \\
\text { comportamentais, elegendo a aptidão } \\
\text { fisica como principal mediador da } \\
\text { saúde. }\end{array}$ \\
\hline \multirow{3}{*}{ Político } & $\begin{array}{l}\text { Concretizado pela união de forças entre a } \\
\text { Universidade e o Sindicato, na tentativa de } \\
\text { atender aos interesses da classe trabalhadora, } \\
\text { com vistas a auxiliar sua organização e } \\
\text { fortalecimento. }\end{array}$ & $\begin{array}{l}\text { Funciona como uma prestação de } \\
\text { serviço, na qual se vende suas } \\
\text { vantagens aos empresários que, } \\
\text { obviamente, atendem prioritariamente a } \\
\text { seus interesses, tais como aumento de } \\
\text { produtividade, redução de licenças } \\
\text { médicas, absenteísmo etc. }\end{array}$ \\
\hline & $\begin{array}{l}\text { Identificamos junto com os trabalhadores e a } \\
\text { entidade sindical os determinantes que } \\
\text { degradam as suas condições de vida e de } \\
\text { saúde. }\end{array}$ & $\begin{array}{l}\text { Mascaram os determinantes que } \\
\text { degradam as condições de vida e de } \\
\text { saúde dos trabalhadores e, em muitos } \\
\text { casos, intensificam a exploração } \\
\text { capitalista. }\end{array}$ \\
\hline & $\begin{array}{l}\text { Procura-se evidenciar as contradições e os } \\
\text { conflitos do ambiente laboral, estimulando o } \\
\text { reconhecimento do poder, historicamente } \\
\text { acumulado pelas instituições dominadoras, } \\
\text { que impende a equidade e justiça social. }\end{array}$ & $\begin{array}{l}\text { Reduz as tensões entre capital e } \\
\text { trabalho, configurando-se como } \\
\text { estratégia que desperta nos } \\
\text { trabalhadores a sensação de "proteção" } \\
\text { e"cuidado". }\end{array}$ \\
\hline \multirow[b]{2}{*}{ Pedagógico } & $\begin{array}{l}\text { Educa pelos princípios de emancipação e } \\
\text { esclarecimento, despertando reflexão crítica. } \\
\text { Os participantes são considerados produtores } \\
\text { de conhecimento. }\end{array}$ & $\begin{array}{l}\text { Atua através de conceitos de adaptação } \\
\text { e compensação das estruturas físicas. A } \\
\text { conscientização nestas práticas é } \\
\text { caracterizada pela transferência de } \\
\text { informações (educação bancária). }\end{array}$ \\
\hline & $\begin{array}{l}\text { Há liberdade de criar e recriar os movimentos, } \\
\text { através de estratégias de cooperação, } \\
\text { participação e solidariedade. Os alunos } \\
\text { realizam as aulas na sede do Sindicato, o que } \\
\text { aproxima a base da entidade. }\end{array}$ & $\begin{array}{l}\text { Os exercícios são padronizados e } \\
\text { dificultam possibilidades de mudanças, } \\
\text { tanto pelos professores, quanto pelos } \\
\text { trabalhadores. A "integração" acontece } \\
\text { como obrigação, por vezes disfarçada } \\
\text { de concessão, e em ambientes mais } \\
\text { apropriados ao trabalho do que às } \\
\text { atividades propostas, que necessitam } \\
\text { ser adaptadas e improvisadas. }\end{array}$ \\
\hline
\end{tabular}

Quadro 1: Comparativo entre propostas de atuação da Educação Física de acordo com os eixos de análise epistemológico, político e pedagógico.

10-Estudo apresentado em Martinez (2007, p. 94).

Pensar a Prática, Goiânia, v. 15, n. 3, p. 551-820, jul./set. 2012 
De fato, ainda existe muito para organizar, planejar e discutir para que um projeto de educação em saúde se torne uma política permanente de uma entidade sindical. Reconhecemos suas conquistas, mas também entendemos suas limitações e contradições, inclusive as nossas. E é neste movimento de ir e vir, avançar e recuar, que fomos construindo suas bases apoiadas nos desejos e aspirações da categoria. As dores que sentimos nas práticas foram amenizadas pelas relações de amizade e solidariedade que se constituíram em nossas aulas, mas cabe lembrar que, elas ainda continuam. No entanto, seu reconhecimento nos torna aptos e capazes de intervir na realidade, pois como nos diz Freire (2000, p. 56) "o futuro não nos faz, nós é que nos refazemos na luta para fazê-lo".

The limitations of labor gymnastics to understand the determinant factors of workers' health in baking institutions

\begin{abstract}
In Brazilian banking institutions, we find a double movement: bankers, with economical and political power, which assures them profits of billions of reais annually; and workers who face the increasing of more intense forms of work domination and the weakness of their resistance capacity. Our objectives are to introduce some worker's health determinant factors in the bank industry and present physical education alternative related to worker's health, applying action research the presumptions. We have concluded that the pedagogical intervention overcame some identified limits in the hegemonic proposals of labor gymnastics. Therefore, we searched to take care of the category's necessities and aspirations by understanding its heath-disease process.
\end{abstract}

Keywords: Worker's Heath. Physical Education. Labor Gymnastic.

Los límites de la gimnasia laboral hacia la comprensión de los determinantes de salud de los trabajadores bancarios

\title{
Resumen
}

En las instituciones bancarias brasileñas encontramos un duplo movimiento: los banqueros, con poder político y económico que les garantiza lucros de mil millones de reales al año; y los trabajadores que enfrentan formas, cada vez más intensas, de dominación del trabajo y enflaquecimiento de sus capacidades de resistencias. Nuestros objetivos fueron anunciar algunos determinantes de salud de los trabajadores bancarios y presentar una posibilidad alternativa de educación física relacionada a la salud, utilizando los presupuestos de la pesquisa-acción. Concluimos que la intervención pedagógica ha superado algunos límites identificados en las propuestas hegemónicas de gimnasia laboral, pues intentamos satisfacer a las necesidades y aspiraciones de la categoría por el entendimiento de su proceso salud-enfermedad. Palabras clave: Salud del Trabajador. Educación Física. Gimnasia Laboral. 


\section{Referências}

AGÊNCIA BRASIL. Quase metade dos bancários sofre agressões morais no trabalho, revela pesquisa. 2006. Disponível em: $<$ http://www.seebfloripa.com.br/> Acesso em: 11 jul. 2006.

ARAÚJO, Â. M. C.; CARTONI, D. M.; JUSTO, C. R. D. M. Reestruturação produtiva e negociação coletiva nos anos 90. Revista Brasileira de Ciências Sociais, v. 16, n. 45, p. 85-112, fev. 2001.

ARRUDA, M. A formação que interessa à classe trabalhadora. Forma e Conteúdo, v. 1, p. 23-27, 1997.

BREILH, J. Epidemiología crítica: ciência emancipadora e interculturalidade. Rio de Janeiro: FIOCRUZ, 2006.

CAMPAÑA, A. Em busca da definição de pautas atuais para o delineamento de estudos sobre condições de vida e saúde. In: BARATA, R. B. (org.). Condições de vida e situação em saúde. Rio de Janeiro: ABRASCO, 1997, p. 115-165.

COLETIVO DE AUTORES. Metodologia do Ensino de Educação Física. São Paulo: Cortez, 1992.

DA ROS, M. A.; VIEIRA, R. C.; CUTOLO, L. R. A. Educação Física - Entre o biológico e o social. Há conflito nisto? Revista Motrivivência, ano XVII, n. 24, p. 107-117, jun. 2005.

FREIRE, P. Pedagogia da Indignação: cartas pedagógicas e outros escritos. São Paulo: UNESP, 2000.

GRISCI, C. L. I.; BESSI, V. G. Modos de trabalhar e de ser na reestruturação bancária. Sociologias, n. 12, p. 160-200, jul./dez. 2004.

HERMÓGENES. Autoperfeição com Hatha Yoga: um clássico sobre saúde e qualidade de vida. 42. ed. Rio de Janeiro: Nova Era, 2004.

JINKINGS, N. Trabalho e resistência na "fonte misteriosa": os bancários no mundo da eletrônica e do dinheiro. Campinas/São Paulo: Editora da Unicamp/Imprensa Oficial de São Paulo, 2002. 
O mister de fazer dinheiro: automatização e subjetividade no trabalho bancário. Paulo: Boitempo Editorial, 1996.

KUNZ, E. Transformação didático-pedagógica do esporte. 5. ed. Ijuí: Editora Unijuí, 2003.

LARANGEIRA, S. M. G. Reestruturação produtiva no setor bancário: a realidade dos anos 90 . Educação \& Sociedade, ano XVIII, n. 61, p. 110-138, dezembro, 1997.

LTP/UnB; SINDICATO DOS BANCÁRIOS DE BRASÍLIA. Laboratório de psicologia do trabalho/ Universidade de Brasília. Saúde mental e trabalho dos bancários (resumo). Brasília, 2004.

MARTINEZ, J. F. N. Superações da Educação (Física) bancária pela Saúde Coletiva: pesquisa-ação no Sindicato de Florianópolis. 2007. 126f. Dissertação (Mestrado em Educação Física) - Programa de Pós-graduação em Educação Física, Universidade Federal de Santa Catarina, Florianópolis, 2007.

MATIELLO JÚNIOR, E.; GONÇALVES, A.; MARTINEZ, J. F. N. Superando riscos na atividade física relacionada à saúde. Movimento (UFRGS. Impresso), Porto Alegre/RS, v. 14, n. 1, p. 39-61, jan/abr. 2008.

MINELLA, A. C. Elites financeiras, sistema financeiro e governo FHC. In: OURIQUES, N. D.; RAMPINELLI, W. J. (Orgs). No fio da navalha: crítica das reformas neoliberais de FHC. São Paulo: Xamã, 1997. p. 165-199.

MERLO, A. R. C.; BARBARINI, N. Reestruturação produtiva no setor bancário brasileiro e sofrimento dos caixas executivos: um estudo de caso. Psicologia \& Sociedade, v. 14, n. 1, p. 103-122, jan./jun. 2002.

MUROFUSE, N. T.; MARZIALE, M. H. P. Mudanças no trabalho e na vida de bancários portadores de lesões por esforços repetitivos: LER. Revista Latino-Americana de Enfermagem, v. 9, n. 4, p. 1925, jul. 2001. 
PALÁCIOS, M.; DUARTE, F.; CÂMARA, V. M. Trabalho e sofrimento psíquico de caixas de agências bancárias na cidade do Rio de Janeiro. Cad. Saúde Pública, v. 18, n. 3. p. 843-851, mai.jun. 2002.

PENNELLA, I. LER: uma jornada de sofrimento no trabalho bancário. 2000. Dissertação (Mestrado em Sociologia) - Faculdade de Filosofia, Letras e Ciências Humanas, Universidade de São Paulo, São Paulo, 2000.

RIGOTTO, R. M. Saúde dos trabalhadores e meio ambiente em tempos de globalização e reestruturação produtiva. Revista Bios da Saúde Ocupacional, v. 25, n. 93-94, p. 9-20, 1998.

SEGNINI, L. R. R.. Reestruturação nos bancos no Brasil: desemprego, subcontratação e intensificação do trabalho. Educação \& Sociedade, v. 20, n. 67, p. 183-209, ago. 1999.

SELIGMANN-SILVA, E. Desgaste mental no trabalho dominado. Rio de Janeiro: UFRJ; Cortez, 1994.

SINDICATO DOS BANCÁRIOS DE PERNAMBUCO. Empregado do Santander com depressão é reintegrado. 2006. Disponível em: $<$ http://www.seebfloripa.com.br> Acesso em: 10 mar. 2006.

TUMOLO, P. S. Da contestação à confrontação: a formação sindical da CUT e a reestruturação capitalista. Campinas: Editora da UNICAMP, 2002.

VERTHEIN, M. A. R.; MINAYO-GOMEZ, C. A construção do "sujeito-doente" em LER. História, Ciências, Saúde, Manguinhos, v. 7, n. 2, p. 327-345, jul./set. 2000.

Recebido em: 22/02/2011

Revisado em: 19/07/2011

Aprovado em: 20/12/2011

Endereço para correspondência

jessicafelix01@yahoo.com.br

Jéssica Felix Nicácio Martinez

Faculdade de Educação Física-Universidade Federal de Goiás

Campus Samambaia, Caixa Postal 131

CEP: 74001-970 Goiânia - Goiás - Brasil

Pensar a Prática, Goiânia, v. 15, n. 3, p. 551-820, jul./set. 2012 